Published in final edited form as:

16 September $27 ; 55(38): 5377-5386$. doi:10.1021/acs.biochem.6b00711.

\title{
Structure of the C-terminal Helical Repeat Domain of Eukaryotic Iongation Factor 2 Kinase
}

\author{
Kevin N. Dalby ${ }^{3,4}$, and Ranajeet Ghose ${ }^{1,2,5,6,}$ \\ ${ }^{3}$ Division of Chemical Biology and Medicinal Chemistry, University of Texas, Austin, TX 78712
}

Abstract

\begin{abstract}
Eukaryotic elongation factor 2 kinase (eEF-2K) phosphorylates its only known physiological ubstrate, elongation factor 2 (eEF-2), which reduces the affinity of eEF-2 for the ribosome and results in an overall reduction in protein translation rates. The $\mathrm{C}$-terminal region of eEF-2K, that is of eEF-2. Using solution NMR methodology, we have determined the structure of a 99-residue fragment from the extreme $\mathrm{C}$-terminus of eEF- $2 \mathrm{~K}\left(\mathrm{eEF}-2 \mathrm{~K}_{627-725}\right)$ that encompasses a region previously suggested to be essential for eEF-2 phosphorylation. eEF-2 $\mathrm{K}_{627-725}$ contains fou frmed by the last thilarity with members of the tetratricopeptide repeat (TPR) family that includes SLRs. The two penultimate helices, aII and aIII, comprise the TPR, and the final helix, aIV, appears to have a previously show or eEF-2 binding, nor isolated eEF-2K $627-725$ inhibit eEF-2 phosphorylation by full-length isolation, does not provide a primary docking site for eEF-2.
\end{abstract}

\footnotetext{
*Address correspondence to: Ranajeet Ghose (rghose@ ccny.cuny.edu, 212-650-6049) and Andrea Piserchio (apiserchio@ccny.cuny.edu, 212-650-5326).

Supporting Information

The Supporting Information is available free of charge on the ACS Publications website at DOI: Three tables and six figures as described in the text.
} 
Eukaryotic elongation factor 2 kinase $(\mathrm{eEF}-2 \mathrm{~K})^{1-3}(725$ residues, $99 \mathrm{kDa})$ is a calmodulindependent member of the a-kinase family that regulates protein synthesis through phosphorylation of its only known cellular target, eukaryotic elongation factor 2 (eEF-2) on a specific threonine residue $(\mathrm{T} 56)^{1-7}$. This post-translational modification impedes the interaction between eEF-2 and the ribosome, thereby reducing global protein synthesis rates $^{4,5,8}$. The regulation of protein translation by eEF-2K is thought to be important in a host of physiological processes, including the regulation of cell cycle progression ${ }^{9}$, synaptic plasticity, learning and the formation of memory ${ }^{10-12}$. It has been suggested that eEF-2K, under conditions of nutrient deprivation, mediates an adaptive response in tumors, thus promoting tumor growth ${ }^{13}$. The role of eEF-2K in the pathogenesis of cancer is further supported by several studies correlating eEF-2K expression with low survival rates in a variety of cancers such as glioblastomas, medulloblastomas ${ }^{14}$ and breast cancer ${ }^{15}$. Recent results suggest that eEF-2K plays a critical role in regulating the Warburg effect by modulating the synthesis of protein phosphatase $2 \mathrm{~A}(\mathrm{PP} 2 \mathrm{~A})^{16}$. In addition, eEF- $2 \mathrm{~K}$ function has been implicated in a variety of neurological conditions such as Alzheimer's disease ${ }^{17,18}$ and clinical depression ${ }^{19}$.

Using a combination of deletions and site-directed mutagenesis supported by bioinformatic tools, previous studies have suggested a domain structure of eEF-2K ${ }^{20,21}$ (Figure 1). eEF-2K contains a sequence $\mathrm{N}$-terminal to its catalytic kinase domain $(\mathrm{KD})$ that takes part in a high-affinity interaction with $\mathrm{Ca}^{2+}-$ loaded calmodulin $(\mathrm{CaM})^{22}$. This interaction initiates a conformational change allowing the efficient auto-phosphorylation of a specific threonine (T348, dark green in Figure 1) located on a regulatory loop (R-loop) C-terminal to the KD. A subsequent interaction involving the phosphorylated T348 and the KD leads to a further conformational change, resulting in the fully active state of the kinase ${ }^{23}$. The eEF-2K KD bears significant sequence homology with the catalytic domains of other a-kinases e.g. the ion-channel kinase TRPM7 (28\% identity) ${ }^{24}$ and myosin heavy chain kinase A (MHCK A, $34 \%$ identity) from Dictyostellium discoideum ${ }^{25}$. In addition to T348, the R-loop, which is predicted to be disordered, contains other phosphorylation sites that lead to negative (red in Figure 1) or positive (green in Figure 1) regulation ${ }^{26}$ of kinase activity.

The C-terminal region/domain (CTD) of eEF-2K is predicted to contain several SEL-1 like helical repeats (SLRs), a structural motif that is known to provide a platform for proteinprotein interactions ${ }^{27}$. This region, that is essential for the physiological function of eEF- $2 \mathrm{~K}$ both in modulating kinase activity and in recognizing substrate ${ }^{28}$, shows poor homology with sequences for which structural information is available. The CTD has been shown to regulate the activity of eEF-2K and it has been suggested that this occurs through a direct interaction with the $\mathrm{KD}^{28}$. It has been further shown that an eEF-2K construct (336-725, that excludes the $\mathrm{N}$-terminal CBD and the KD but includes the R-loop and the entire CTD) can be co-preciptated with eEF-2, suggesting that this region contains the binding site for eEF-2 ${ }^{21}$. Deletion of the extreme C-terminus (711-725) of eEF-2K results in the loss of kinase activity against eEF-2 but not against a peptide substrate, MH-1, leading to the suggestion that this region plays a role in recognizing eEF- $2^{28}$.

Given the fact that the structure of intact full-length eEF-2K is not yet available, we undertook the characterization of the structural elements comprising the CTD using solution 
NMR spectroscopy. The rationale behind this choice is two-fold: (1) While a model for the KD has been derived using the structures of TRPM7 and MHCKA as templates, and this model has proved to be robust for the analysis of small molecule functional modulators ${ }^{29,} 30$, the poor similarity of the CTD sequence with those of known structure makes homology modeling difficult. (2) A structure of the CTD or of relevant fragments thereof should provide a basis for deciphering the nature of the interaction between the CTD and the KD and indeed with the substrate, eEF-2.

As a first step towards this goal, we obtained the solution structure of a 99-residue Cterminal fragment of eEF-2K (627-725, denoted eEF-2 $\left.\mathrm{K}_{627-725}\right)$ that encodes the final two SLRs predicted by an analysis of the eEF-2K sequence against the PFAM database ${ }^{31}$ (Figure 1). This construct includes the region (711-718) that has been suggested to be required for the phosphorylation of eEF-2 ${ }^{28}$. The structure of eEF-2 $\mathrm{K}_{627-725}$, presented here, along with our recent structure of the eEF-2K CBD in complex with $\mathrm{Ca}^{2+} / \mathrm{CaM}^{22}$ represents the first high-resolution structural information on the unique enzyme that is eEF-2K. Our data provides a structural framework to interpret the effects of the deletions/mutations at the $\mathrm{C}$ terminus of eEF-2K that impede its ability to phosphorylate eEF-2 ${ }^{28}$. This data, in combination with preliminary competition assays presented here, suggest that this loss of activity towards eEF-2 is the result of structural destabilization of eEF-2K resulting from the delections/mutations rather than a loss of the primary binding site for eEF-2 that does not appear to be contained uniquely within the isolated eEF-2K $\mathrm{K}_{627-725}$ fragment.

\section{MATERIALS AND METHODS}

\section{Protein expression and purification}

The C-terminal fragment of eEF-2K (S627-E725; 99 residues; eEF-2K $\mathrm{K}_{627-725}$ ) was cloned into a pET15b expression vector (Novagen) between the NdeI and BamHI restriction sites and transformed into BL21 DE3 cells (New England Biolabs) for expression. The cells were plated on ampicillin plates and incubated overnight at $37^{\circ} \mathrm{C}$. A single colony was inoculated into $10 \mathrm{~mL}$ of $\mathrm{M} 9$ minimal medium and grown overnight at $37{ }^{\circ} \mathrm{C}$. After centrifugation at $4{ }^{\circ} \mathrm{C}$ for 20 minutes at $4000 \mathrm{~g}$, the cells from the starter culture were inoculated into $0.5 \mathrm{~L}$ of M9 minimal medium containing $1 \mathrm{~g}$ of ${ }^{15} \mathrm{~N}$-labeled ammonium chloride and $2 \mathrm{~g}$ of ${ }^{13} \mathrm{C}$ labeled glucose as the sole nitrogen and carbon sources, respectively. The cells were grown at $37^{\circ} \mathrm{C}$ until the culture reached an $\mathrm{OD}_{600}$ of 0.8 , at which point the temperature was reduced to $18{ }^{\circ} \mathrm{C}$ and expression was induced by addition of $0.4 \mathrm{mM}$ isopropyl $\beta$-D-1thiogalactopyranoside (IPTG). Cells were subsequently grown for 20 hours and harvested by centrifugation at $4{ }^{\circ} \mathrm{C}$ for 30 minutes at $3000 \mathrm{~g}$. Harvested cell pellets were re-suspended in $40 \mathrm{~mL}$ of lysis buffer (20 mM Tris, $0.1 \% \beta$-mercaptoethanol, $10 \mathrm{mM}$ imidazole and 1 tablet of Roche Complete Mini EDTA-free inhibitor tablet, at $\mathrm{pH}$ 7.5); all subsequent steps described below were carried out at $4{ }^{\circ} \mathrm{C}$. The cells were lysed by sonication and cell debris was removed by centrifugation at $4{ }^{\circ} \mathrm{C}$ for 30 minutes at $15550 \mathrm{~g}$. The soluble lysate was added to a $3 \mathrm{~mL}$ (bed volume) Ni-NTA affinity column (Qiagen) previously equilibrated with lysis buffer and incubated for 1 hour on a rotary agitator. The column was then washed extensively with washing buffer ( $20 \mathrm{mM}$ Tris, $0.1 \% \beta$-mercaptoethanol, $20 \mathrm{mM}$ imidazole, $\mathrm{pH} 7.5$ ) and subsequently the bound protein was eluted with $50 \mathrm{~mL}$ of elution buffer $(20 \mathrm{mM}$ 
Tris, $0.1 \% \beta$-mercaptoethanol, $250 \mathrm{mM}$ imidazole, $\mathrm{pH}$ 7.5). The N-terminal His 6 -tag was cleaved with the addition of $\sim 50$ units of human a-thrombin (Enzyme Research Laboratories) while being dialyzed overnight into the cleavage buffer (20 mM Tris, $0.1 \% \beta-$ mercaptoethanol, $5 \mathrm{mM}$ EDTA, $\mathrm{pH}$ 7.5). The effectiveness of cleavage was monitored by $15 \%$ SDS-PAGE gels. The cleavage reaction was quenched by the addition of $0.1 \mathrm{mM}$ AEBSF (Sigma-Aldrich). The protein was then concentrated using spin columns and further purified by gel-filtration chromatography using a Superdex 75 10/300 GL (GE HealthCare Biosciences) column pre-equilibrated with NMR buffer ( $50 \mathrm{mM}$ phosphate, $4 \mathrm{mM}$ DTT, $\mathrm{pH}$ 6.5). Fractions containing pure eEF-2 $\mathrm{K}_{627-725}$ were collected and concentrated using a spin column to final concentrations ranging from 300 to $600 \mu \mathrm{M}$ for NMR experiments.

The Y712A/Y713A, Y712A, Y713A, and E717A mutants of eEF-2K $627-725$ were generated using the QuikChange Multi Site-Directed Mutagenesis Kit (Agilent) and appropriately designed primers. The mutated plasmid was transformed into XL10-Gold ultracompetent $E$. coli cells supplied with the kit. For protein expression, Y712A/Y713A and E717A constructs were transformed into BL21 DE3 and expressed using the protocol described above for wild-type eEF-2 $\mathrm{K}_{627-725}$. The Y713A mutant was expressed at $37{ }^{\circ} \mathrm{C}$ for 4 hours after IPTG induction. The Y712A construct did not express under any of the conditions. The purification protocol for all of the mutants was the same as wild-type protein, as described above.

\section{Resonance assignment}

All NMR experiments were recorded at $25^{\circ} \mathrm{C}$ using Varian Inova $(600 \mathrm{MHz})$ or Bruker Avance spectrometers $(600,700,800 \mathrm{MHz})$ equipped with cryogenic probes capable of applying pulsed-field gradients along the z-axis. All NMR data were processed and analyzed using the NMRPipe ${ }^{32}$ and the NMRViewJ ${ }^{33}$ software suites, respectively. Backbone resonance assignments were obtained using standard backbone-directed triple-resonance strategies ${ }^{34}$ using $\mathrm{HNCO} / \mathrm{HN}(\mathrm{CA}) \mathrm{CO}$ and $\mathrm{HNCACB} / \mathrm{CBCA}(\mathrm{CO}) \mathrm{NH}$ pairs. Sidechain resonance assignments were obtained though $\mathrm{H}(\mathrm{CCO}) \mathrm{NH}-\mathrm{TOCSY},(\mathrm{H}) \mathrm{C}(\mathrm{CO}) \mathrm{NH}-\mathrm{TOCSY}$, and HCCH-TOCSY ${ }^{34}$. Details of these experiments are provided in Table S1. Distance constraints were obtained from $3 \mathrm{D}{ }^{15} \mathrm{~N}$-edited NOESY-HSQC, ${ }^{13} \mathrm{C}$-aliphatic edited and ${ }^{13} \mathrm{C}$ aromatic NOESY-HSQC experiments, using mixing times of $150 \mathrm{~ms}$ in all cases. Aromatic assignments were obtained from the ${ }^{13} \mathrm{C}$-aromatic edited NOESY-HSQC supplemented by a $2 \mathrm{D}^{1} \mathrm{H}-{ }^{1} \mathrm{H}$ NOESY experiment. ${ }^{13} \mathrm{C}$-aliphatic edited and homonuclear NOESY experiments were carried out in $\mathrm{D}_{2} \mathrm{O}$-based buffers. Experimental details of the NOESY experiments are provided in Table S2. Methionine $\varepsilon$-methyl groups were assigned using the NOESY experiments in combination with 3D HMBC and 3D LRCH experiments ${ }^{35}$ (see Table S1 for details). The assigned chemical shifts have been deposited into the BMRB with accession code 30135 .

\section{Measurement of residual dipolar couplings}

Partially oriented samples for residual dipolar coupling (RDC) measurements experiments were obtained by adding Pf1 phage (ASLA Ltd.) ${ }^{36}$ directly into the NMR sample (the $\mathrm{pH}$ was manually adjusted to 6.5) for a final concentration of $15 \mathrm{mg} / \mathrm{mL}$ phage and $300 \mu \mathrm{M}$ of eEF-2 $\mathrm{K}_{627-725}$. Amide ${ }^{15} \mathrm{~N}-{ }^{1} \mathrm{H}$ RDCs were collected at $600 \mathrm{MHz}$ using $2 \mathrm{D}{ }^{15} \mathrm{~N}$ IPAP ${ }^{37}$ 
pulse sequences (spectral windows of 12 and 28 ppm with 512 and 128 complex points in the direct and indirect dimensions, respectively) on both aligned $\left({ }^{2} \mathrm{H}\right.$ quadrupolar splitting $\approx$ $23 \mathrm{~Hz}$ ) and isotropic samples. The measured RDCs were analyzed using the PALES software suite ${ }^{38}$ and utilizing the initial structural ensemble generated using distance and dihedral angle constraints only.

\section{Relaxation measurements}

${ }^{15} \mathrm{~N}$ longitudinal $\left(\mathrm{R}_{1}\right)$ and transverse $\left(\mathrm{R}_{2}\right)$ relaxation rates were obtained at $600 \mathrm{MHz}$ using standard pulse sequences ${ }^{39}$. The following relaxation delays were used $-\mathrm{R}_{1}: 10 \mathrm{~ms}, 50 \mathrm{~ms}$,

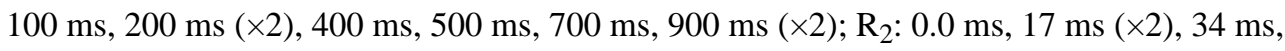
$51 \mathrm{~ms}, 68 \mathrm{~ms}, 85 \mathrm{~ms}, 102 \mathrm{~ms}(\times 2), 136 \mathrm{~ms}, 170 \mathrm{~ms}, 203 \mathrm{~ms}$. Steady-state $\left\{{ }^{1} \mathrm{H}\right\}-{ }^{15} \mathrm{~N}$ NOE experiments were also collected at $600 \mathrm{MHz}$ using the pulse sequence of Ferrage et. al. ${ }^{40}$ using a saturation time of $5 \mathrm{~s}$ and an overall delay of $7 \mathrm{~s}$. All relaxation experiments used sweep-widths of 12 and $28 \mathrm{ppm}$ with 512 and 128 complex points in the direct and indirect dimensions, respectively.

\section{Structure calculations}

Structure calculations were performed using ARIA2.3 (CNS1.2) following published protocols ${ }^{41}$. Briefly, TALOS $+{ }^{42}$ was used to obtain dihedral angle constraints from chemical shifts $\left({ }^{1} \mathrm{H},{ }^{1} \mathrm{Ha},{ }^{13} \mathrm{Ca},{ }^{13} \mathrm{C} \beta,{ }^{13} \mathrm{C}\right.$ and $\left.{ }^{15} \mathrm{~N}\right)$, and peak intensities of the 3D NOESY experiments were introduced directly into ARIA to derive ambiguous distance restraints. Spin-diffusion correction was introduced for all NOESY spectra ${ }^{43}$. The required correlation time was estimated using the measured ${ }^{15} \mathrm{~N}$ relaxation rates from the structured parts of the protein.

Structure calculations were carried out within the standard ARIA protocol using PROLSQ ${ }^{44}$ for non-bonded parameters, 20000 and 40000 steps were used for the high temperature $(10000 \mathrm{~K})$ torsion angle simulated annealing ( $27 \mathrm{fs}$ integration time) and for the two Cartesian cooling phases ( $1000 \mathrm{~K}, 50 \mathrm{~K}$ as final temperatures, 3 fs integration time). Network anchoring was introduced in the first three iterations of the protocol, floating chirality was implemented for the pro-chiral moieties. A log-harmonic potential ${ }^{45}$ and the automatic restraints weight protocol were implemented during the second cooling phase. During this stage the weight for the dihedral restraints was reduced to 5 , and hydrogen bonds restraints were introduced for those residues predicted by TALOS $+{ }^{42}$ to be in a helical conformation. RDCs for the helical fragments (excluding those from aI: 634-637) were introduced as inter-vector projection angle restraints ${ }^{46}$ using the dipolar_segid.py script from the HADDOCK software suite ${ }^{47}$. The alignment tensor components necessary for the conversion were estimated using the program PALES ${ }^{38}$ and the measured RDC values on a preliminary NMR structural ensemble obtained without RDC restraints. Those angular restraints limiting the torsional space by more than $25 \%$ were introduced in the ARIA calculations starting from the fifth iteration. Of the 400 structures generated in this way, 179 were refined with 24000 steps of a Cartesian dynamics protocol in explicit water ${ }^{48}$. Unless specifically mentioned, default values were used for all ARIA input variables. The final structures were analyzed using PROCHECK-NMR $2.0^{49}$ and the WHATIF web-server ${ }^{50}$. Structures in the NMR ensemble were aligned using the McLachlan algorithm as 
implemented in the program PROFIT 3.1 and visualized using open-source PyMOL 1.7.6. The NMR ensemble has been deposited into the PDB with ID 5KS5.

\section{Competition assays}

For the competition assays described below, eEF-2K was expressed and purified using protocols described previously ${ }^{51}$. Established procedures were utilized to purify wheat germ eEF- $2^{52}$ and yeast eEF- $2^{53}$, for use in the peptide and eEF- $2 \mathrm{~K}_{627-725}$ inhibition assays, respectively. Wheat germ eEF-2 $2^{54,55}$ and yeast eEF-2 $2^{56}$ have been shown to be phosphorylated by mammalian eEF-2Ks with similar kinetic parameters as those derived from mammalian cells.

Competition assays were performed at $30{ }^{\circ} \mathrm{C}$ in buffer B (25 mM HEPES, pH 7.6, $2 \mathrm{mM}$ DTT, $10 \mu \mathrm{g} / \mathrm{mL}$ BSA, $10 \mathrm{mM} \mathrm{MgCl}_{2}, 100 \mu \mathrm{M}$ EGTA, $150 \mu \mathrm{M} \mathrm{CaCl}_{2}$ and $\left.2 \mu \mathrm{M} \mathrm{CaM}\right)$ at $\mathrm{pH}$ 7.6. For each reaction, $10 \mu \mathrm{M}$ eEF-2 was incubated with either 0 ( $25 \mathrm{mM}$ HEPES) or 500 $\mu \mathrm{M}$ C-terminal peptide (acetyl- ${ }^{707}$ RLANQYYQKAEEAWAQMEE ${ }^{725}$-amide) for $30 \mathrm{~min}$ at $30{ }^{\circ} \mathrm{C}$ followed by incubation with $0.5 \mathrm{nM}$ eEF-2K for an additional $10 \mathrm{~min}$. The reaction was initiated by the addition of $1 \mathrm{mM}\left[\gamma^{-32} \mathrm{P}\right]$-ATP $(100-1000 \mathrm{cpm} / \mathrm{pmol})$ in a total volume of $100 \mu \mathrm{L}$. At set time points $(60,120,180,240,300$ and $360 \mathrm{sec}), 10 \mu \mathrm{L}$ aliquots were taken and spotted onto P81 cellulose filters (Whatman, $2 \times 2 \mathrm{~cm}$ ). The filter papers were then washed thrice in $50 \mathrm{mM}$ phosphoric acid (15 min each wash), once in acetone (15 min) and finally dried. The amount of labeled peptide associated with each paper was determined by measuring the cpm on a Packard 1500 scintillation counter. All experiments were performed in duplicate.

To test inhibition of eEF-2 phosphorylation by eEF- $2 \mathrm{~K}_{627-725}$, eEF-2K (final concentration $0.2 \mathrm{nM}$ ) was added to buffer $\mathrm{B}(\mathrm{pH}$ 7.5, $6 \mu \mathrm{M}$ eEF-2) containing either eEF-2K $627-725$ (20 $\mu \mathrm{M}$ ) or an equivalent volume of buffer and equilibrated at $27^{\circ} \mathrm{C}$ for $3 \mathrm{~min}$, followed by initiation with $1 \mathrm{mM}\left[\gamma^{-32} \mathrm{P}\right]-\mathrm{ATP}$, as above. The reaction was allowed to proceed for $5 \mathrm{~min}$, at which time $10 \mu \mathrm{L}$ was removed into Quench buffer (5X SDS-PAGE buffer $+50 \mathrm{mM}$ EDTA) and boiled for 5 minutes. Quenched samples were subjected to SDS-PAGE analyses, and autoradiography images were acquired using a Typhoon phosphorimager. Quantification of eEF-2 band intensities in the autoradiographs, reported as arbitrary units, was carried out in Image ${ }^{57}$ after first linearizing the .gel file with the "Linearize GelData" plugin (https:// imagej.nih.gov/ij/plugins/linearize-gel-data.html). Additional quantification of phosphate incorporated into eEF-2 was carried out by scintillation counting of the excised eEF-2 bands from the SDS-PAGE gel, using the specific activity of $\left[\gamma_{-}{ }^{32} \mathrm{P}\right]-\mathrm{ATP}$ and the amount of eEF-2 per lane (60 pmol) to calculate the $\mathrm{mol} / \mathrm{mol}$ ratio of phosphate/eEF-2.

\section{RESULTS AND DISCUSSION}

\section{Choice of the eEF-2K $\mathrm{K}_{627-725}$ construct}

It has been previously reported, based on sequence analysis, that the CTD of eEF-2K is highly a-helical and is predicted to contain several SLRs ${ }^{21,28}$. In order to isolate, express and structurally characterize this region, we first attempted to localize the domain structure of the region by analyzing the D473-E725 fragment of eEF2K using bio-informatics tools. 
An analysis of the eEF-2K sequence against the PFAM database ${ }^{31}$ leads to the prediction of four SEL-1 like repeats (SLRs): L528-G562, T590-D609, E636-M647 and A672-A699. Combining this prediction with the results of the GeneSilico metaserver ${ }^{58}$ to identify secondary structural elements and disordered regions, we designed the eEF-2 $\mathrm{K}_{627-725}$ construct to include the last two SLRs and the extreme C-terminus that has been shown to be required for the phosphorylation of eEF-2 ${ }^{28}$.

\section{Resonance assignment of eEF-2 $\mathrm{K}_{627-725}$}

The ${ }^{15} \mathrm{~N},{ }^{1} \mathrm{H}$ HSQC spectrum of eEF-2 $\mathrm{K}_{627-725}$ (Figure S1) shows dispersion that is characteristic of high a-helical content and suggests the presence of well-ordered regions. Using standard backbone-directed triple resonance experiments (see Table S1), we were able to assign all of the main-chain amide ${ }^{15} \mathrm{~N},{ }^{1} \mathrm{H},{ }^{1} \mathrm{Ha},{ }^{13} \mathrm{Ca},{ }^{13} \mathrm{C}$ ' resonances for non-proline residues (excluding the 4 additional amino acids remaining after thrombin cleavage). For the 3 prolines, all the ${ }^{1} \mathrm{Ha},{ }^{13} \mathrm{Ca}$, and ${ }^{13} \mathrm{C}$ ' resonances could be assigned. Additionally, we obtained assignments for $100 \%$ and $99.5 \%$ of sidechain ${ }^{1} \mathrm{H}$ and ${ }^{13} \mathrm{C}$ resonances, respectively. $92.4 \%$ and $84.3 \%$ of aromatic ${ }^{1} \mathrm{H}$ and heteronuclear $\left({ }^{13} \mathrm{C},{ }^{15} \mathrm{~N}\right)$ resonances, respectively, were also assigned. $88.9 \%$ and $84.2 \%$, respectively, of ${ }^{1} \mathrm{H}$ and ${ }^{15} \mathrm{~N}$ atoms belonging to the amino sidechains of Asn and Gln could be assigned. These assignments were then utilized to obtain distance constraints from a variety of NOESY (Table S2) datasets and combined with chemical shift based backbone dihedral angle constraints using TALOS $+{ }^{42}$ and ${ }^{15} \mathrm{~N}-{ }^{1} \mathrm{H}$ RDCs to determine the structure of eEF- $2 \mathrm{~K}_{627-725}$.

\section{Solution structure of eEF-2K $627-725$}

As expected from chemical shift analysis, eEF-2 $\mathrm{K}_{627-725}$ contains four helical segments. The structural ensemble (Figure 2) confirms that these helical elements are localized to the regions encompassing (in at least $90 \%$ of the structures comprising the NMR ensemble) W634-A637 (aI), R664-T677 (aII), P686-E702 (aIII), and G706-Q722 (aIV). While helix aI comprises a single helical turn in all structures of the NMR ensemble, this helical segment extends from Q633 to W640 in about 60\% of the structures, suggesting significant disorder at the extremities. Indeed, this helix appears to be more dynamic and structurally ill-defined than the others (see below). In contrast, the last three helices are ordered and fold into an antiparallel helical bundle, where individual helices (aII-aIV) stack sequentially on each other and form an elongated shape centered on aIII. The overall fold is stabilized by a number of van der Waals contacts involving contiguous helices, specifically between a II (involving residues Y665, L668, A669, E671, A672, E673, L675, F676) and aIII (R688, S689, L692, Y693, Q695, A696, A699, A700, A703), between aIII (P686, Q687, G690, D691, Y693, T694, A696, A697, A700, M701) and aIV (L708, A709, Y712, Y713, K715, A716, A719, W720). All of the listed residues participate in multiple contacts, each detectable in at least $90 \%$ of the structures that comprise the NMR ensemble. Further, a subset of these residues, namely Y665, A669, F676 on aII, Y693, A696, A700 on aIII, and Y712, A719 on aIV, stabilize the helical core by forming simultaneous contacts with both of the other two helices of the bundle (Figure 3).

As expected, from the RMSD values for the structures that comprise the NMR ensemble (Table 1), the last three helices (aII-aIV) are largely ordered, displaying large values for the 
reduced spectral density function at zero-frequency, $\mathrm{J}(0)(2.6 \pm 0.4 \mathrm{~ns} / \mathrm{rad})$, and small values at high-frequency, $\mathrm{J}\left(0.87 \omega_{\mathrm{H}}\right)(7.0 \pm 1.3 \mathrm{ps} / \mathrm{rad})$ (see below, Figure 4$)$. The compactness of the tertiary fold involving helices aII-aIV is the consequence of a large number (168) of long range ( $\searrow, i+5)$ contacts that leads to small pairwise RMSDs among the structures (see Table 1) that constitute the NMR ensemble. In contrast, this network of long range contacts is missing for aI, and as a result, it assumes a variety of different orientations with respect to the helical bundle in the NMR ensemble (Figure 2). That this is indeed a true feature of this region of eEF-2 $\mathrm{K}_{627-725}$ rather than an inadequacy in the NOE assignment or in the structure calculation protocol is reinforced by the fact that the order parameters predicted from the chemical shifts (RCI S ${ }^{2}$, Figure $\left.5 \mathrm{~A}\right)^{59}$ are lower for helix aI $(0.73 \pm 0.05)$ than for the helical core comprising a II- $\alpha \mathrm{IV}(0.87 \pm 0.06)$. Additionally, $\alpha \mathrm{I}$ is characterized by lower $\mathrm{J}(0)$ $(2.0 \pm 0.3 \mathrm{~ns} / \mathrm{rad})$ and significantly higher $\mathrm{J}\left(0.87 \omega_{\mathrm{H}}\right)(12.7 \pm 1.4 \mathrm{ps} / \mathrm{rad})$ values than the alIaIV core, indicating a larger amount of disorder on the fast timescale (Figure 4). A plot of $J\left(\omega_{N}\right)$ versus $J(0)$ shows that aI occupies a region distinct from the remaining helices (Figure S2). Further, while the amide ${ }^{15} \mathrm{~N}-{ }^{1} \mathrm{H}$ RDC values for the helical bundle (aII-aIV) tend to be negative in sign and are generally quite large in overall magnitude $(-19 \pm 10 \mathrm{~Hz}$, Figure 5B), for helix aI, the RDC values range from -1.2 to $2.4 \mathrm{~Hz}$, and are not dissimilar from those observed in the contiguous, mostly unstructured Y641-Q660 loop (RDC=1.6 \pm 1.3 $\mathrm{Hz}$ ). The RDC and relaxation data combined strongly suggest that $\mathrm{aI}$ is not anchored to the helical core comprised of aII-aIV. This disorder is largely facilitated by the highly dynamic nature of the aI-aII loop encompassing Y641-Q660 $\left(\mathrm{J}\left(0.87 \omega_{\mathrm{H}}\right)=18.4 \pm 3.5 \mathrm{ps} / \mathrm{rad}\right)$, and indeed in the structures of the NMR ensemble this region does not converge around a unique fold (Figure 2). A statistical analysis of the secondary structure elements however indicates a propensity for various turn-like conformations in this area, as suggested by the presence of several medium range NOEs.

\section{Similarities with known structural families}

SLRs, together with the tetratrico peptide repeats (TPR) and the pentatrico peptide repeats (PPR), form a class of proteins called solenoids ${ }^{60}$. Solenoids are comprised of basic repeating helix(A)-turn-helix(B) motifs that stack onto each other forming a super-helical assembly driven largely by van Der Waals interactions connecting the second (B) and, to a lesser extent, the first (A) helix of a given structural unit to the first helix (A') belonging to the following repeat ${ }^{61,62}$. The structurally related SLR, TPR and PPR motifs ${ }^{27}$ differ only slightly in their characteristic consensus sequences. In fact, SLR motifs are considered to be a sub-class of TPR motifs ${ }^{27}$. Compared to TPRs, SLRs are characterized by longer loops between the two helices comprising the individual motifs, and shorter loops connecting different repeat units. The consensus sequences themselves, however are loosely defined for TPRs and SLRs alike, as they require few specific residues to be conserved, preferring instead, broad classes of sidechains (small, large, hydrophobic etc.) for the individual positions, and in fact few positions are truly invariant ${ }^{63}$ (Figure S3). As a consequence, accurate sequence-based prediction of such entities in a protein of unknown structure can be challenging ${ }^{64}$. Indeed, based on the structure of eEF-2K $627-725$ the length of the loop between a II and aIII (9 amino-acids) is more consistent with an SLR rather than a TPR. However a query to the DALI server ${ }^{65}, 66$ for structures in the PDB homologous to eEF- $2 \mathrm{~K}_{627-725}$ produces matches with a large number of motifs belonging to the TPR family 
but not the SLR sub-family. While there is little difference between the structures of the individual repeats between the canonical TPR and SLR motifs, the largest difference lies in their super-helical parameters (resulting from the arrangement of multiple repeats) with the former being narrower than the latter ${ }^{27}$. Therefore, whether eEF-2 $\mathrm{K}_{627-725}$ indeed conforms to a TPR motif or to an SLR motif can only be confirmed once the structure of the intact CTD is available.

Super-helices of the TPR family often terminate with a single helical motif, termed capping or solubility helix, that stabilizes the sequence. Upon analysis of the 10 best non-redundant entries that resulted from the DALI query (See Table S3) we noted two distinct sets of patterns for the alignments (Figure S4, Table S3). In some of the cases, the aII-aIV helical core of eEF-2 $\mathrm{K}_{627-725}$ aligns best with a C-terminal repeat, with aIV aligning with the corresponding $\mathrm{C}$-terminal capping helix. In others, a II and a III structurally align with a particular TPR hairpin in the matching protein, while aIV aligns with the A' helix belonging to the following repeat module. Obviously the first scenario appears to be the more appropriate, given the $\mathrm{C}$-terminal location of the eEF-2 $\mathrm{K}_{627-725}$ fragment. A structural alignment with an idealized TPR sequence is of interest because it allows the comparison of sidechain packing observed for eEF-2 $\mathrm{K}_{627-725}$ to that of a structure derived from the consensus sequence (Figure 6). Of the seven signature residues identified in the hairpin motif (in addition to one in the intervening loop) by Main and coworkers ${ }^{62}$, two are fully conserved (Y693 and A696), and three other positions are compatible with the SMART ${ }^{67,68}$ consensus requirements (L668/W, A672/G, L675/Y, S689/A). The only sidechain which appears to diverge from both the SMART and the signature residue is found at position 671 (E671/L). In the idealized TPR structure, the signature residues in a given helix form contacts with the complementary helix within the same hairpin, and with helices from the neighboring repeats. E671 on aII is indeed involved in van Der Waals interactions with aIII residues. According to the TPR global propensities calculated by Main et al. ${ }^{62}$, the leucine residue in this position (7 in their work; 10 in Figure 6A) has much lower propensity value compared to the other signature residues. The second highest propensity value for this sidechain is an arginine, suggesting that charged residues are tolerated at this position.

As mentioned above, aI does not pack with the aII-aIV core, it however contains a number of aromatic and hydrophobic residues. This would suggest that aI likely corresponds to the second (B) helix of the penultimate repeat, while the first (A) helix is not included within the boundaries of the eEF-2 $\mathrm{K}_{627-725}$ construct. The lack of tertiary structure would indicate that the missing interactions with the first helix (A) are required to stabilize the packing against the following repeat, and it is in fact likely that the boundaries of helix aI itself will be different in the context of a fully formed domain. The loop between aI and aII does not contain any defined secondary structure elements, but it does contain several hydrophobic sidechains, so it is possible that this region could adopt different structural features in the context of the full length protein.

\section{Functional role of the extreme C-terminus of eEF-2K}

Next, we investigated whether the structure of eEF-2K $627-725$ could be used to obtain insight into the mutational data of Pigott et. $\mathrm{al}^{28}$. It was shown that the deletion of the last fifteen 
amino acids (711-725) are sufficient to abolish eEF-2 phosphorylation, with minimal effects on the phosphorylation of the MH-1 peptide. Based on the structure of eEF-2 $\mathrm{K}_{627-725}$, deletion of the last 15 residues $(\Delta 15)$ would result in the elimination of most of the $\mathrm{C}$ terminal capping helix (aIV), and with it, multiple stabilizing interactions with the remaining helices, most notably the interactions involving Y712, Y713, K715, A716, A719 and W720. Most importantly, Y712 and, to some extent, the smaller A720, take part in multiple interactions with both aII and aIII and stabilize helical core (Figure 3). In contrast the deletion of the last 8 residues $(\Delta 8)$, and therefore only of the smaller A719 but not of Y712, would be expected to have much more modest effect, as is seen ${ }^{28}$. For the Q711-E718 segment, the removal of which completely abolishes eEF-2 phosphorylation, the stabilizing interactions involving Y712 are eliminated.

Pigott et. al ${ }^{28}$ also mutated several conserved residues in the 711-718 region of full-length eEF-2K to test for their effects on eEF-2 phosphorylation. Mutation of each of the two highly conserved tyrosine residues (Y712, Y713) reduced the level of phosphorylation of eEF-2. In contrast, a Y712A/Y713A double mutation lead to the complete loss in the ability of eEF-2K to phosphorylate eEF-2. As in the case of the deletion mutants ( $\Delta 15$ and the $711-$ 718 segment), none of these single or double mutations had comparable effects on the ability to phosphorylate the MH-1 peptide. As described above, Y712 makes many hydrophobic contacts within the helical core of eEF-2 $\mathrm{K}_{627-725}$, therefore its alteration would be expected to destabilize the three helix bundle to a greater extent than a Y713A mutation. Despite our best efforts, we failed to express the Y712A mutant and test its structural characteristics by NMR. However, we successfully expressed the Y713A mutant, and found that the perturbations in the ${ }^{15} \mathrm{~N},{ }^{1} \mathrm{H}$ HSQC spectrum of this mutant when compared to wild-type eEF-2K $\mathrm{K}_{627-725}$, were small and largely localized near the site of the mutation (Figure S5A). In contrast, the ${ }^{15} \mathrm{~N},{ }^{1} \mathrm{H}$ HSQC spectrum of the $\mathrm{Y} 712 \mathrm{~A} / \mathrm{Y} 713 \mathrm{~A}$ double mutant reflected a characteristic cigar shape expected in unfolded proteins (Figure S5B). Interestingly, another C-terminal mutation, E717A, not only does not compromise eEF-2 phosphorylation, but in fact enhances the capability of eEF-2K to phosphorylate both eEF-2 and $\mathrm{MH}-1^{28}$. In our NMR structure, E717 that is part of the C-terminal helix (aIV), is largely exposed to solvent, and the E717A mutation does not appear to affect the overall fold of this region (Figure S5C). As mentioned previously, the CTD of eEF-2K closely associates with the KD and modulates its activity. A bioinformatics analysis ${ }^{69}$ indicates that E717 coevolves with $\mathrm{R} 200$ on the $\mathrm{KD}$, a residue predicted to be exposed in our previously reported homology model of the $\mathrm{KD}^{29}$. This could indicate that a possible E717-R200 salt-bridge provides a point of contact between the CTD and the KD, and that perhaps the E717A mutation alters the interface between the KD and CTD, thereby modulating kinase activity.

Finally, we performed a set of preliminary experiments to test the suggested role of the CTD, specifically of its extreme C-terminus, in recognizing eEF-2. First, we tested the ability of a 19-residue peptide (R707-E725) that encompasses the 711-718 segment to inhibit eEF-2K mediated phosphorylation of eEF-2. We found no difference in the rate of phosphorylation of eEF-2 in the absence or the presence of $500 \mu \mathrm{M}$ peptide (Figure S6A). Curiously, not only did the intact eEF- $2 \mathrm{~K}_{627-725}$ not provide any inhibition, but its presence resulted in a slight increase ( 14\%) in the rate of phosphorylation of eEF-2 (Figure S6B). Additionally, a low level of phosphorylation (data not shown) of eEF-2 $\mathrm{K}_{627-725}$ itself was 
seen. This, as in the case of the E717A mutant, discussed above, could be the result of a reorganization of the KD/CTD interface, due to inter-molecular binding of eEF-2K $627-725$ to the KD in competition with the intra-molecular binding of the intact CTD (also underscored by eEF-2K $627-725$ phosphorylation). These results, taken together, suggest that neither the linear sequence encoded by the extreme C-terminus of eEF-2K nor the eEF-2K $627-725$ construct in isolation can efficiently engage eEF-2.

\section{CONCLUSIONS}

Using NMR methodology, we have determined the solution structure of a 99-residue construct (eEF-2 $\left.\mathrm{K}_{627-725}\right)$ that encodes the extreme C-terminus of eEF-2K. The structure of eEF-2 $\mathrm{K}_{627-725}$ reveals that this region contains a 3-helix core that is composed of a TPR-like motif capped by a $\mathrm{C}$-terminal helix. The $\mathrm{N}$-terminal end of the construct also contains a helix that is largely unstable and does not pack against the C-terminal helical core. We expect that this helix is stabilized by additional interactions within the intact CTD that are absent in the construct studied here. It is likely to be part of another, not yet characterized, TPR-like motif. Further, the structure of this fragment provides a framework to interpret the functional data of Pigott et. $\mathrm{al}^{28}$ that suggest that this region is required for the phosphorylation of eEF-2. The structural fold of the C-terminal helical core (R664-E725) of eEF-2K $\mathrm{K}_{627-725}$, as well as the NMR spectra of its $\mathrm{Y} 712 \mathrm{~A} / \mathrm{Y} 713 \mathrm{~A}$ mutant, suggests that in the context of the full-length eEF- $2 \mathrm{~K}$ this double mutation as well as the $\Delta 15 \mathrm{C}$-terminal truncation abolish eEF-2 phosphorylation by destabilizing the C-terminal capping helix and compromising the structural integrity of the CTD. Thus, the lack of activity towards eEF-2 appears to be the result of structural destabilization rather than a specific perturbation of a binding surface. Consistent with these observations, neither a peptide that includes the 711718 region of eEF- $2 \mathrm{~K}$, nor the eEF- $2 \mathrm{~K}_{627-725}$ construct in its entirety, can interfere with the ability of full-length eEF- $2 \mathrm{~K}$ to phosphorylate eEF-2. Thus, our data indicates that the major determinants for the eEF-2 recognition are not uniquely contained within the last 15 residues of eEF-2K, as previously proposed ${ }^{28}$. However, it is possible that the engagement of the other parts of the CTD, and perhaps also of the $\mathrm{KD}$, are required for eEF-2 $\mathrm{K}_{627-725}$ (and the 711-718 segment therein) to attain the appropriate conformation to enable the binding of eEF-2. Clearly, additional work, both structural and biochemical, are necessary to fully resolve this issue.

\section{Supplementary Material}

Refer to Web version on PubMed Central for supplementary material.

\section{Acknowledgments}

\section{FUNDING}

This research has been supported by the following grants from the NIH: GM084278 (to RG), GM059802 (to KND) and G12 MD007603 (partial support of the CCNY NMR facilities); Welch Foundation: F-1390 (to KND). RG is a member of the New York Structural Biology Center, a NYSTAR facility. NW acknowledges support from the United States Department of Education GAANN award P200A120211. IS was supported by CUNY C-SURP award through a grant from the Alfred P. Sloan Foundation (2014-6-25). This manuscript was written while RG was a Program Director at the NSF (MCB); his IRD activities are supported by award MCB 1557303. 
The authors are grateful to Drs. James Aramini (ASRC) and Hsin Wang (CCNY) for their help with NMR experiments and Dr. Sébastien Alphonse for his assistance with structure calculations. The authors also thank Fatlum Hajredini for the evolutionary covariance analysis.

\section{References}

1. Ryazanov AG. Elongation factor-2 kinase and its newly discovered relatives. FEBS Lett. 2002; 514:26-29. [PubMed: 11904175]

2. Ryazanov AG, Ward MD, Mendola CE, Pavur KS, Dorovkov MV, Wiedmann M, ErdjumentBromage H, Tempst P, Parmer TG, Prostko CR, Germino FJ, Hait WN. Identification of a new class of protein kinases represented by eukaryotic elongation factor-2 kinase. Proc Natl Acad Sci USA. 1997; 94:4884-4889. [PubMed: 9144159]

3. Ryazanov AG. $\mathrm{Ca}^{2+} /$ calmodulin-dependent phosphorylation of elongation factor 2 . FEBS Lett. 1987; 214:331-334. [PubMed: 3569528]

4. Ryazanov AG, Davydova EK. Mechanism of elongation factor 2 (EF-2) inactivation upon phosphorylation. Phosphorylated EF-2 is unable to catalyze translocation. FEBS Lett. 1989; 251:187-190. [PubMed: 2753158]

5. Ryazanov AG, Shestakova EA, Natapov PG. Phosphorylation of elongation factor 2 by EF-2 kinase affects rate of translation. Nature. 1988; 334:170-173. [PubMed: 3386756]

6. Nairn AC, Palfrey HC. Identification of the major $M_{r} 100,000$ substrate for calmodulin-dependent protein kinase III in mammalian cells as elongation factor-2, J. Biol. Chem. 1987; 262:17299_ 17303.

7. Nairn AC, Bhagat B, Palfrey HC. Identification of calmodulin-dependent protein kinase III and its major $M_{r}$ 100,000 substrate in mammalian tissues, Proc. Natl Acad Sci USA. 1985; 82:7939-7943.

8. Carlberg U, Nilsson A, Nygard O. Functional properties of phosphorylated elongation factor 2. Eur J Biochem. 1990; 191:639-645. [PubMed: 2390990]

9. Smith EM, Proud CG. cdc2-cyclin B regulates eEF2 kinase activity in a cell cycle- and amino aciddependent manner. EMBO J. 2008; 27:1005-1016. [PubMed: 18337751]

10. Gildish I, Manor D, David O, Sharma V, Williams D, Agarwala U, Wang X, Kenney JW, Proud CG, Rosenblum K. Impaired associative taste learning and abnormal brain activation in kinasedefective eEF2K mice. Learning Mem. 2012; 19:116-125.

11. Sutton MA, Taylor AM, Ito HT, Pham A, Schuman EM. Postsynaptic decoding of neural activity: eEF2 as a biochemical sensor coupling miniature synaptic transmission to local protein synthesis. Neuron. 2007; 55:648-661. [PubMed: 17698016]

12. Taha E, Gildish I, Gal-Ben-Ari S, Rosenblum K. The role of eEF2 pathway in learning and synaptic plasticity. Neurobiol Learning Mem. 2013; 105:100-106.

13. Tekedereli I, Alpay SN, Tavares CD, Cobanoglu ZE, Kaoud TS, Sahin I, Sood AK, LopezBerestein G, Dalby KN, Ozpolat B. Targeted silencing of elongation factor 2 kinase suppresses growth and sensitizes tumors to doxorubicin in an orthotopic model of breast cancer. PLoS One. 2012; 7:e41171. [PubMed: 22911754]

14. Leprivier G, Remke M, Rotblat B, Dubuc A, Mateo A-RF, Kool M, Agnihotri S, El-Naggar A, Yu B, Prakash Somasekharan S, Faubert B, Bridon G, Tognon CE, Mathers J, Thomas R, Li A, Barokas A, Kwok B, Bowden M, Smith S, Wu X, Korshunov A, Hielscher T, Northcott PA, Galpin JD, Ahern CA, Wang Y, McCabe MG, Collins VP, Jones RG, Pollak M, Delattre O, Gleave ME, Jan E, Pfister SM, Proud CG, Derry WB, Taylor MD, Sorensen PH. The eEF2 kinase confers resistance to nutrient deprivation by blocking translation elongation. Cell. 2013; 153:1064-1079. [PubMed: 23706743]

15. Meric-Bernstam F, Chen H, Akcakanat A, Do KA, Lluch A, Hennessy BT, Hortobagyi GN, Mills GB, Gonzalez-Angulo AM. Aberrations in translational regulation are associated with poor prognosis in hormone receptor-positive breast cancer. Breast Cancer Res. 2012; 14:R138. [PubMed: 23102376]

16. Cheng Y, Ren X, Yuan Y, Shan Y, Li L, Chen X, Zhang L, Takahashi Y, Yang JW, Han B, Liao J, Li Y, Harvey H, Ryazanov A, Robertson GP, Wan G, Liu D, Chen AF, Tao Y, Yang JM. eEF-2 kinase is a critical regulator of Warburg effect through controlling PP2A-A synthesis. Oncogene. 2016 in press. 
17. Li X, Alafuzoff I, Soininen H, Winblad B, Pei JJ. Levels of mTOR and its downstream targets 4EBP1, eEF2, and eEF2 kinase in relationships with tau in Alzheimer's disease brain. FEBS J. 2005; 272:4211-4220. [PubMed: 16098202]

18. Ma T, Chen Y, Vingtdeux V, Zhao H, Viollet B, Marambaud P, Klann E. Inhibition of AMPActivated protein kinase signaling alleviates impairments in hippocampal synaptic plasticity induced by amyloid $\beta$. J Neurosci. 2014; 34:12230-12238. [PubMed: 25186765]

19. Monteggia LM, Gideons E, Kavalali ET. The role of eukaryotic elongation factor 2 kinase in rapid antidepressant action of ketamine. Biol Psych. 2013; 73:1199-1203.

20. Diggle TA, Seehra CK, Hase S, Redpath NT. Analysis of the domain structure of elongation factor-2 kinase by mutagenesis. FEBS Lett. 1999; 457:189-192. [PubMed: 10471776]

21. Pavur KS, Petrov AN, Ryazanov AG. Mapping the functional domains of elongation factor-2 kinase. Biochemistry. 2000; 39:12216-12224. [PubMed: 11015200]

22. Lee KH, Alphonse S, Piserchio A, Tavares CDJ, Wellmann RM, Dalby KN, Ghose R. Structural basis for the recognition of eukaryotic elongation factor 2 kinase by calmodulin. Structure. 2016 in press.

23. Tavares CDJ, Ferguson SB, Giles DH, Wang Q, Wellmann RM, O'Brien JP, Warthaka M, Brodbelt JS, Ren P, Dalby KN. The molecular mechanism of eukaryotic elongation factor 2 kinase activation. J Biol Chem. 2014; 289:23901-23916. [PubMed: 25012662]

24. Yamaguchi H, Matsushita M, Nairn AC, Kuriyan J. Crystal structure of the atypical protein kinase domain of a TRP channel with phosphotransferase activity. Mol Cell. 2001; 7:1047-1057. [PubMed: 11389851]

25. Ye Q, Crawley SW, Yang Y, Cote GP, Jia Z. Crystal structure of the alpha-kinase domain of Dictyostelium myosin heavy chain kinase A. Sci Signal. 2010; 3:ra17. [PubMed: 20197546]

26. Kenney JW, Moore CE, Wang X, Proud CG. Eukaryotic elongation factor 2 kinase, an unusual enzyme with multiple roles. Adv Biol Regul. 2014; 55C:15-27.

27. Mittl PR, Schneider-Brachert W. Sel1-like repeat proteins in signal transduction. Cell Signal. 2007; 19:20-31. [PubMed: 16870393]

28. Pigott CR, Mikolajek H, Moore CE, Finn SJ, Phippen CW, Werner JM, Proud CG. Insights into the regulation of eukaryotic elongation factor 2 kinase and the interplay between its domains. Biochem J. 2012; 442:105. [PubMed: 22115317]

29. Devkota AK, Edupuganti R, Yan C, Shi Y, Jose J, Wang Q, Kaoud TS, Cho EJ, Ren P, Dalby KN. Reversible covalent inhibition of eEF-2K by carbonitriles. ChemBioChem. 2014; 15:2435-2442. [PubMed: 25224652]

30. Edupuganti R, Wang Q, Tavares CD, Chitjian CA, Bachman JL, Ren P, Anslyn EV, Dalby KN. Synthesis and biological evaluation of pyrido[2,3-d]pyrimidine-2,4-dione derivatives as eEF-2K inhibitors. Bioorg Med Chem. 2014; 22:4910-4916. [PubMed: 25047940]

31. Finn RD, Coggill P, Eberhardt RY, Eddy SR, Mistry J, Mitchell AL, Potter SC, Punta M, Qureshi M, Sangrador-Vegas A, Salazar GA, Tate J, Bateman A. The Pfam protein families database: towards a more sustainable future. Nucleic Acids Res. 2016; 44:D279-285. [PubMed: 26673716]

32. Delaglio F, Grzesiek S, Vuister GW, Zhu G, Pfeifer J, Bax A. NMRPipe: a multidimensional spectral processing system based on UNIX pipes. J Biomol NMR. 1995; 6:277-293. [PubMed: 8520220]

33. Johnson BA. Using NMRView to visualize and analyze the NMR spectra of macromolecules. Meth Mol Biol. 2004; 278:313-352.

34. Sattler M, Schleucher J, Griesinger C. Heteronuclear multidimensional NMR experiments for the structure determination of proteins in solution employing pulsed field gradients. Prog NMR Spectrosc. 1999; 34:93-158.

35. Bax A, Delaglio F, Grzesiek S, Vuister GW. Resonance assignment of methionine methyl groups and $\chi 3$ angular information from long-range proton-carbon and carbon-carbon $\mathrm{J}$ correlation in a calmodulin-peptide complex. J Biomol NMR. 1994; 4:787-797. [PubMed: 7812153]

36. Zweckstetter M, Bax A. Characterization of molecular alignment in aqueous suspensions of Pf1 bacteriophage. J Biomol NMR. 2001; 20:365-377. [PubMed: 11563559]

37. Ottiger M, Delaglio F, Bax A. Measurement of J and dipolar couplings from simplified twodimensional NMR spectra. J Magn Reson. 1998; 131:373-378. [PubMed: 9571116] 
38. Zweckstetter M. NMR: prediction of molecular alignment from structure using the PALES software. Nature Protoc. 2008; 3:679-690. [PubMed: 18388951]

39. Cavanagh, J., Fairbrother, WJ., III, AJP, Mark, R., Skelton, NJ. Protein NMR Spectroscopy. 2. Academic Press; San Diego: 2007.

40. Ferrage F, Cowburn D, Ghose R. Accurate sampling of high-frequency motions in proteins by steady-state ${ }^{15} \mathrm{~N}-\left\{{ }^{1} \mathrm{H}\right\}$ nuclear Overhauser effect measurements in the presence of cross-correlated relaxation, J. Am. Chem Soc. 2009; 131:6048-6049.

41. Habeck M, Rieping W, Linge JP, Nilges M. NOE assignment with ARIA 2.0: the nuts and bolts. Meth Mol Biol. 2004; 278:379-402.

42. Shen Y, Delaglio F, Cornilescu G, Bax A. TALOS+: a hybrid method for predicting protein backbone torsion angles from NMR chemical shifts. J Biomol NMR. 2009; 44:213-223. [PubMed: 19548092]

43. Linge JP, Habeck M, Rieping W, Nilges M. Correction of spin diffusion during iterative automated NOE assignment. J Magn Reson. 2004; 167:334-342. [PubMed: 15040991]

44. Engh R, Huber R. Accurate bond and angle parameters. Acta Crystallogr A. 1991; 47:392-400.

45. Nilges M, Bernard A, Bardiaux B, Malliavin T, Habeck M, Rieping W. Accurate NMR structures through minimization of an extended hybrid energy. Structure. 2008; 16:1305-1312. [PubMed: 18786394]

46. Meiler J, Blomberg N, Nilges M, Griesinger C. A new approach for applying residual dipolar couplings as restraints in structure elucidation. J Biomol NMR. 2000; 16:245-252. [PubMed: 10805131]

47. Dominguez C, Boelens R, Bonvin AMJJ. HADDOCK: a protein-protein docking approach based on biochemical or biophysical information. J Am Chem Soc. 2003; 125:1731-1737. [PubMed: 12580598]

48. Linge JP, Williams MA, Spronk CAEM, Bonvin AMJJ, Nilges M. Refinement of protein structures in explicit solvent. Proteins. 2003; 50:496-506. [PubMed: 12557191]

49. Laskowski RA, Rullmannn JA, MacArthur MW, Kaptein R, Thornton JM. AQUA and PROCHECK-NMR: programs for checking the quality of protein structures solved by NMR. J Biomol NMR. 1996; 8:477-486. [PubMed: 9008363]

50. Vriend G. WHAT IF: a molecular modeling and drug design program. J Mol Graph. 1990; 8:5256. 29. [PubMed: 2268628]

51. Tavares CDJCD, O'Brien JPJP, Abramczyk OO, Devkota AKAK, Shores KSKS, Ferguson SBSB, Kaoud TSTS, Warthaka MM, Marshall KDKD, Keller KMKM, Zhang YY, Brodbelt JSJS, Ozpolat BB, Dalby KNKN. Calcium/calmodulin stimulates the autophosphorylation of elongation factor 2 kinase on Thr-348 and Ser-500 to regulate its activity and calcium dependence. Biochemistry. 2012; 51:2232-2245. [PubMed: 22329831]

52. Lax SR, Lauer SJ, Browning KS, Ravel JM. Purification and properties of protein synthesis initiation and elongation factors from wheat germ. Meth Enzymol. 1986; 118:109-128. [PubMed: 3512960]

53. Jorgensen R, Carr-Schmid A, Ortiz PA, Kinzy TG, Andersen GR. Purification and crystallization of the yeast elongation factor eEF2. Acta Crystallogr D Biol Crystallogr. 2002; 58:712-715. [PubMed: 11914505]

54. Smailov SK, Lee AV, Iskakov BK. Study of phosphorylation of translation elongation factor 2 (EF-2) from wheat germ. FEBS Lett. 1993; 321:219-223. [PubMed: 8386679]

55. Abramczyk O, Tavares CD, Devkota AK, Ryazanov AG, Turk BE, Riggs AF, Ozpolat B, Dalby KN. Purification and characterization of tagless recombinant human elongation factor 2 kinase (eEF-2K) expressed in Escherichia coli. Prot Expr Purif. 2011; 79:237-244.

56. Mitsui K, Brady M, Palfrey HC, Nairn AC. Purification and characterization of calmodulindependent protein kinase III from rabbit reticulocytes and rat pancreas. J Biol Chem. 1993; 268:13422-13433. [PubMed: 8514778]

57. Schneider CA, Rasband WS, Eliceiri KW. NIH Image to ImageJ: 25 years of image analysis. Nature Meth. 2012; 9:671-675.

58. Kurowski MA, Bujnicki JM. GeneSilico protein structure prediction meta-server. Nucleic Acids Res. 2003; 31:3305-3307. [PubMed: 12824313] 
59. Berjanskii MV, Wishart DS. A simple method to predict protein flexibility using secondary chemical shifts. J Am Chem Soc. 2005; 127:14970-14971. [PubMed: 16248604]

60. Kobe B, Kajava AV. When protein folding is simplified to protein coiling: the continuum of solenoid protein structures. Trends Biochem Sci. 2000; 25:509-515. [PubMed: 11050437]

61. Zeytuni N, Zarivach R. Structural and functional discussion of the tetra-trico-peptide repeat, a protein interaction module. Structure. 2012; 20:397-405. [PubMed: 22404999]

62. Main ER, Xiong Y, Cocco MJ, D'Andrea L, Regan L. Design of stable alpha-helical arrays from an idealized TPR motif. Structure. 2003; 11:497-508. [PubMed: 12737816]

63. D'Andrea LD, Regan L. TPR proteins: the versatile helix. Trends Biochem Sci. 2003; 28:655-662. [PubMed: 14659697]

64. Karpenahalli MR, Lupas AN, Soding J. TPRpred: a tool for prediction of TPR-, PPR- and SEL1like repeats from protein sequences. BMC Bioinform. 2007; 8:2.

65. Holm L, Laakso LM. Dali server update. Nucleic Acids Res. 2016; 44:351-355.

66. Holm L, Sander C. Touring protein fold space with Dali/FSSP. Nucleic Acids Res. 1998; 26:316319. [PubMed: 9399863]

67. Schultz J, Milpetz F, Bork P, Ponting CP. SMART, a simple modular architecture research tool: identification of signaling domains. Proc Natl Acad Sci USA. 1998; 95:5857-5864. [PubMed: 9600884]

68. Letunic I, Doerks T, Bork P. SMART: recent updates, new developments and status in 2015. Nucleic Acids Res. 2015; 43:D257-260. [PubMed: 25300481]

69. Baker FN, Porollo A. CoeViz: a web-based tool for coevolution analysis of protein residues. BMC Bioinform. 2016; 17:119. 


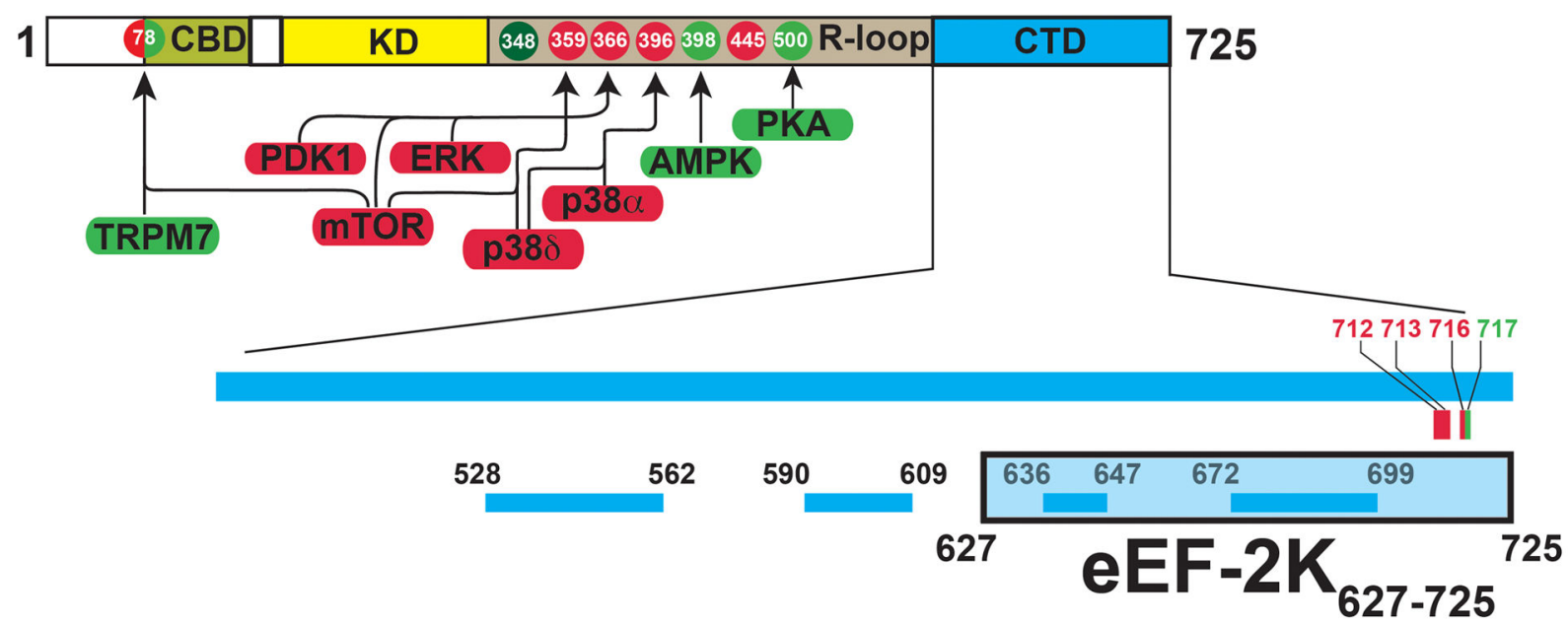

Figure 1.

Schematic representation of the domain structure of eEF-2K. The N-terminal calmodulinbinding domain (CBD), catalytic kinase domain (KD) and the C-terminal domain (CTD) are shown. The region between the KD and CTD is known as the regulatory loop (R-loop) that contains both upregulating (green) and downregulating (red) phosphorylation sites. The kinases that target these phosphorylation sites are indicated. The N-terminal S78 can act as both an activating as well as an inhibitory site. T348, the autophosphorylation of which constitutes a key step in the activation eEF-2K is shown in dark green. The specific $\mathrm{C}$ terminal mutations, discussed in the text that either reduce (red) or enhance (green) eEF-2 phosphorylation, are indicated. The lower panel shows the location of the PFAM-predicted SEL-1 like repeats (SLRs). The eEF-2K $627-725$ construct (shaded light blue) includes the last two predicted SLRs. 
(A)

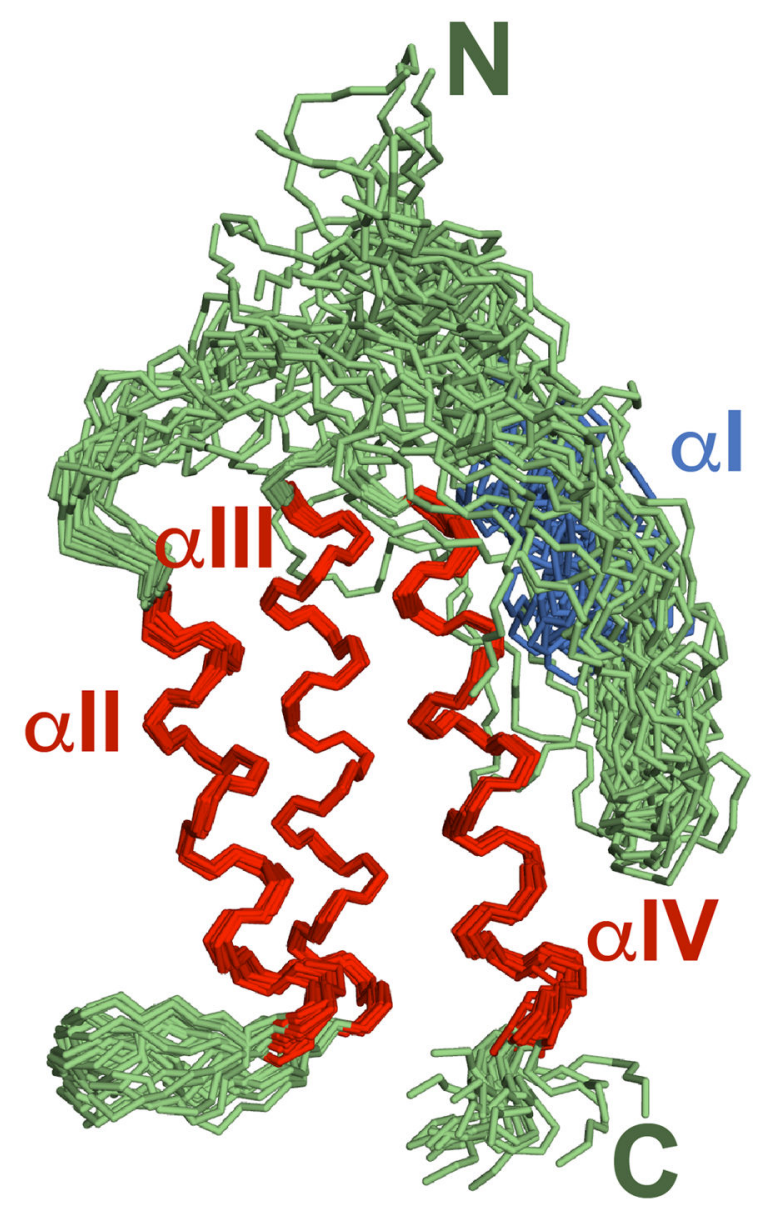

(B)

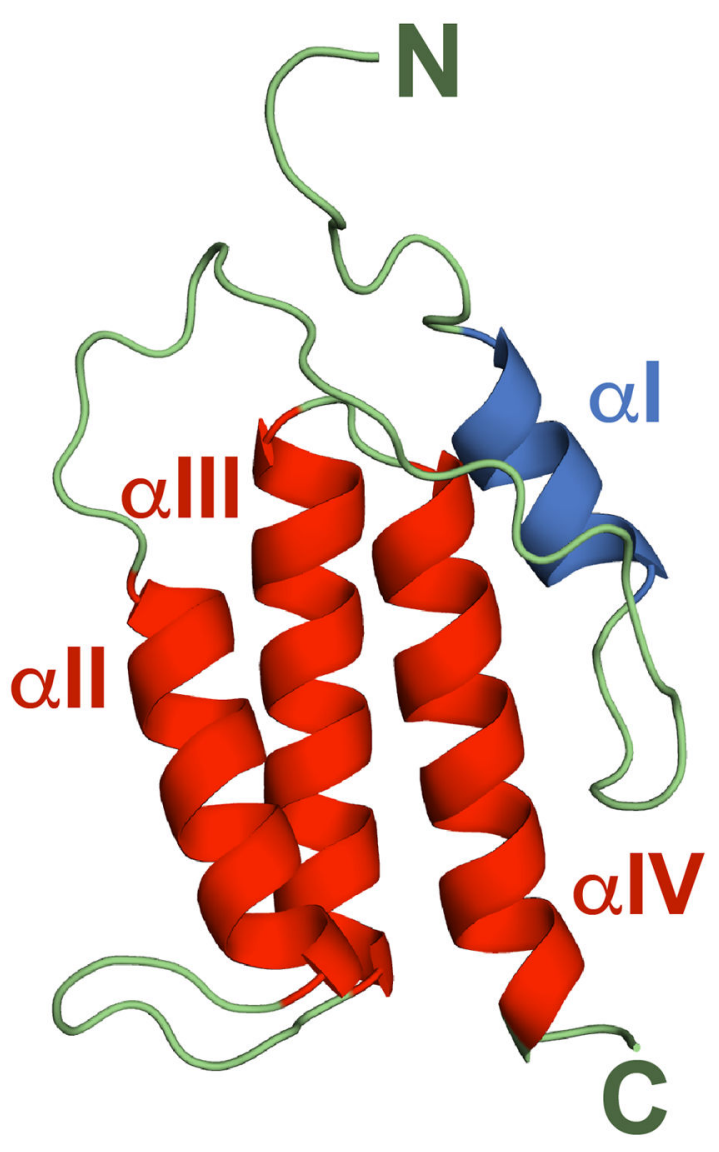

Figure 2.

(A) The NMR structural ensemble of eEF-2 $\mathrm{K}_{627-725}$ consisting of the 20 lowest energy structures overlaid on helices aII, aIII and aIV (using backbone heavy atoms). (B) Ribbon representation of the lowest energy structure showing the location of the four helices. The helices (aII-aIV) that comprise the helical core are shown in red and the N-terminal helix (aI) is shown in blue. Loops are shown in green. 

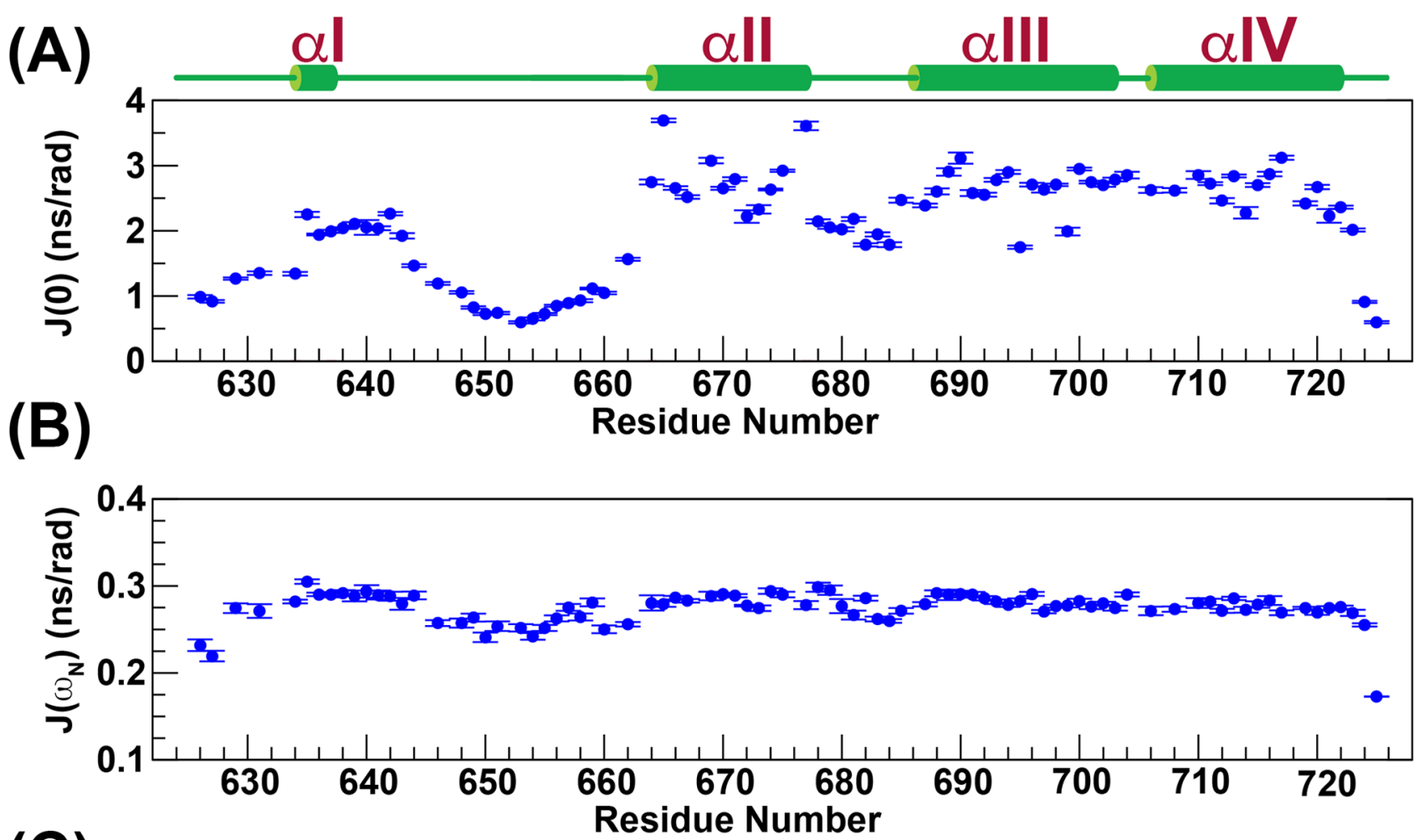

(C)

\section{Residue Number}

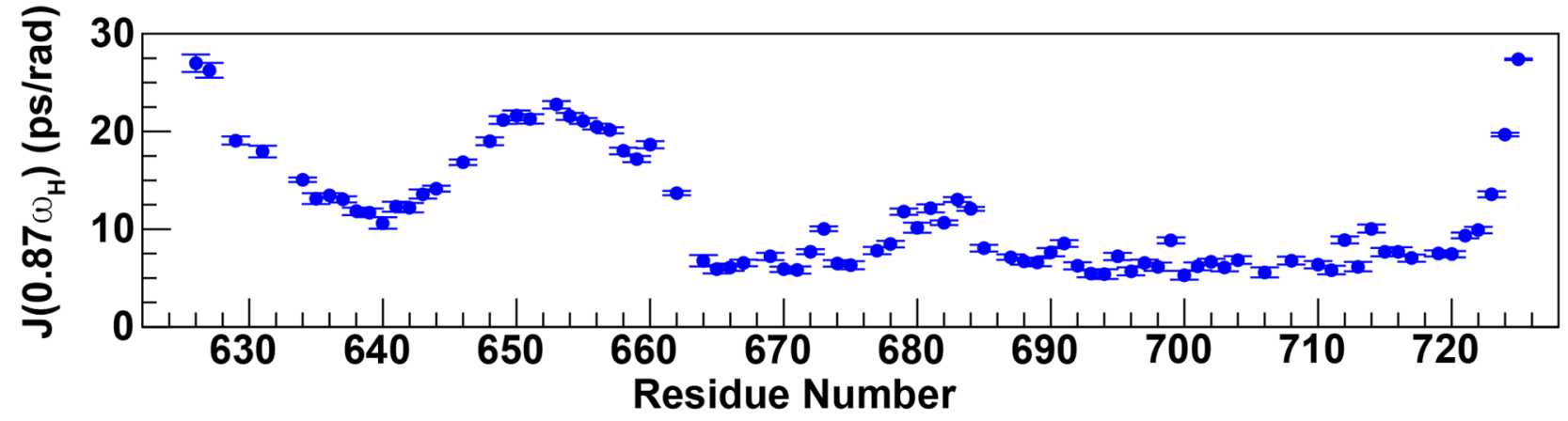

Figure 3.

Structure of the helical core, comprising helices aII-aIV. Residues that make key interhelical contacts are shown as sticks. Residues that stabilize the core by making contacts involving all three helices are shown and labeled in red; other colors indicate helix-helix contacts as shown in the key on the top right. 

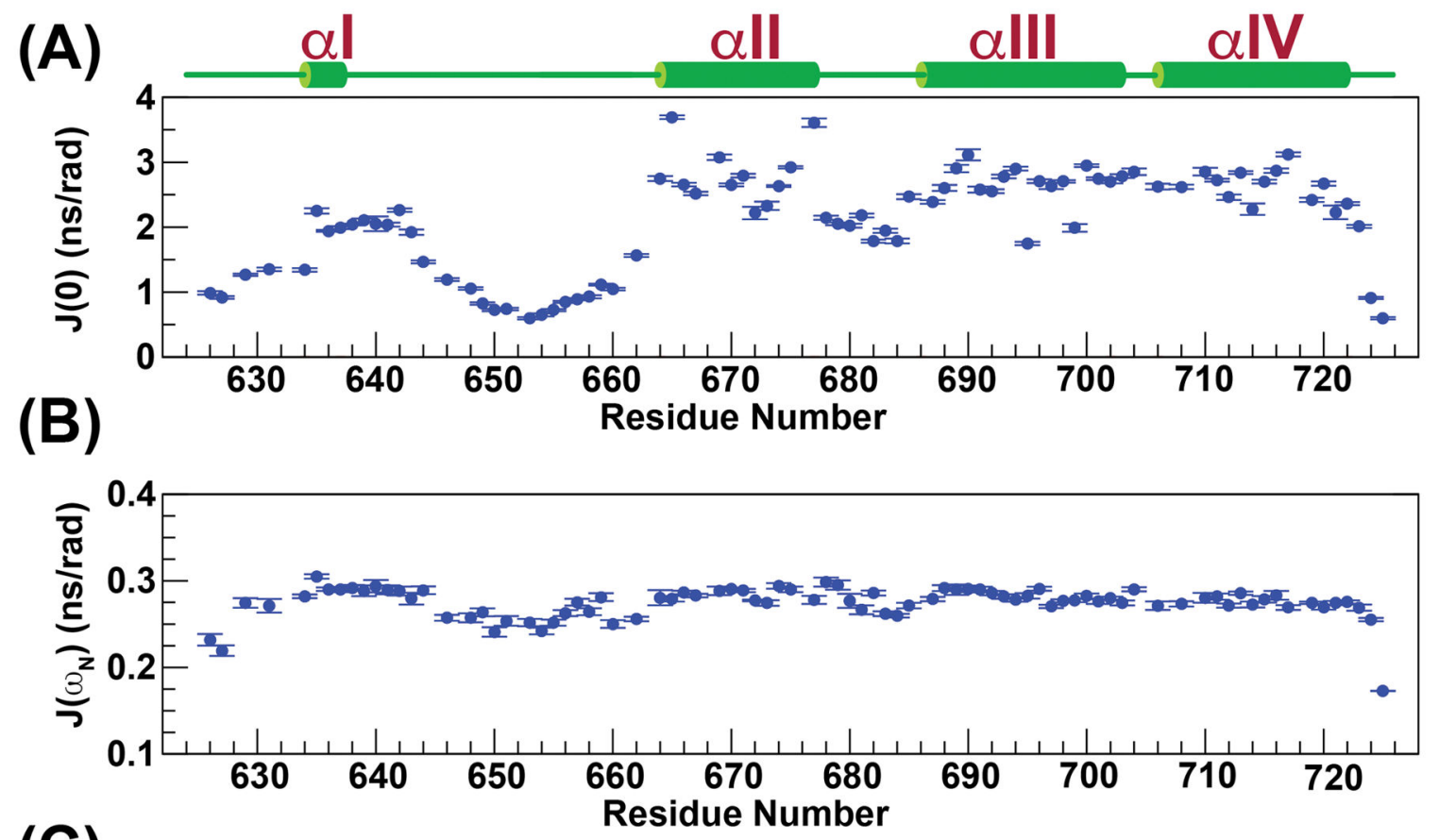

(C)

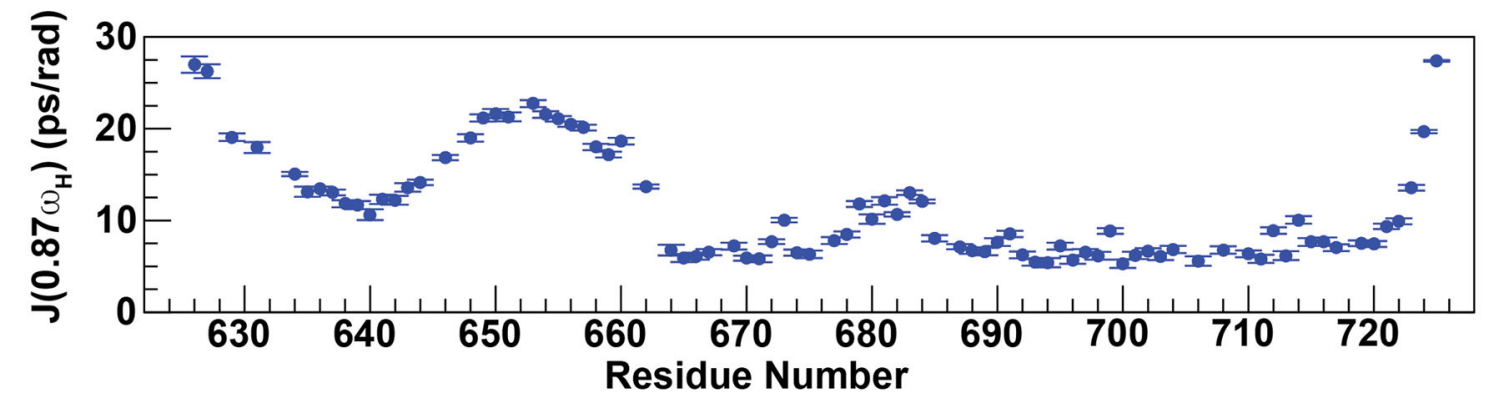

Figure 4.

Reduced spectral density functions at $0(\mathbf{A}), \omega_{\mathrm{N}}(\mathbf{B})$ and $0.87 \omega_{\mathrm{H}}(\mathbf{C})$ frequencies calculated from backbone ${ }^{15} \mathrm{~N}$ relaxation data measured at $600 \mathrm{MHz}$ and $25^{\circ} \mathrm{C}$ are plotted against residue number. 

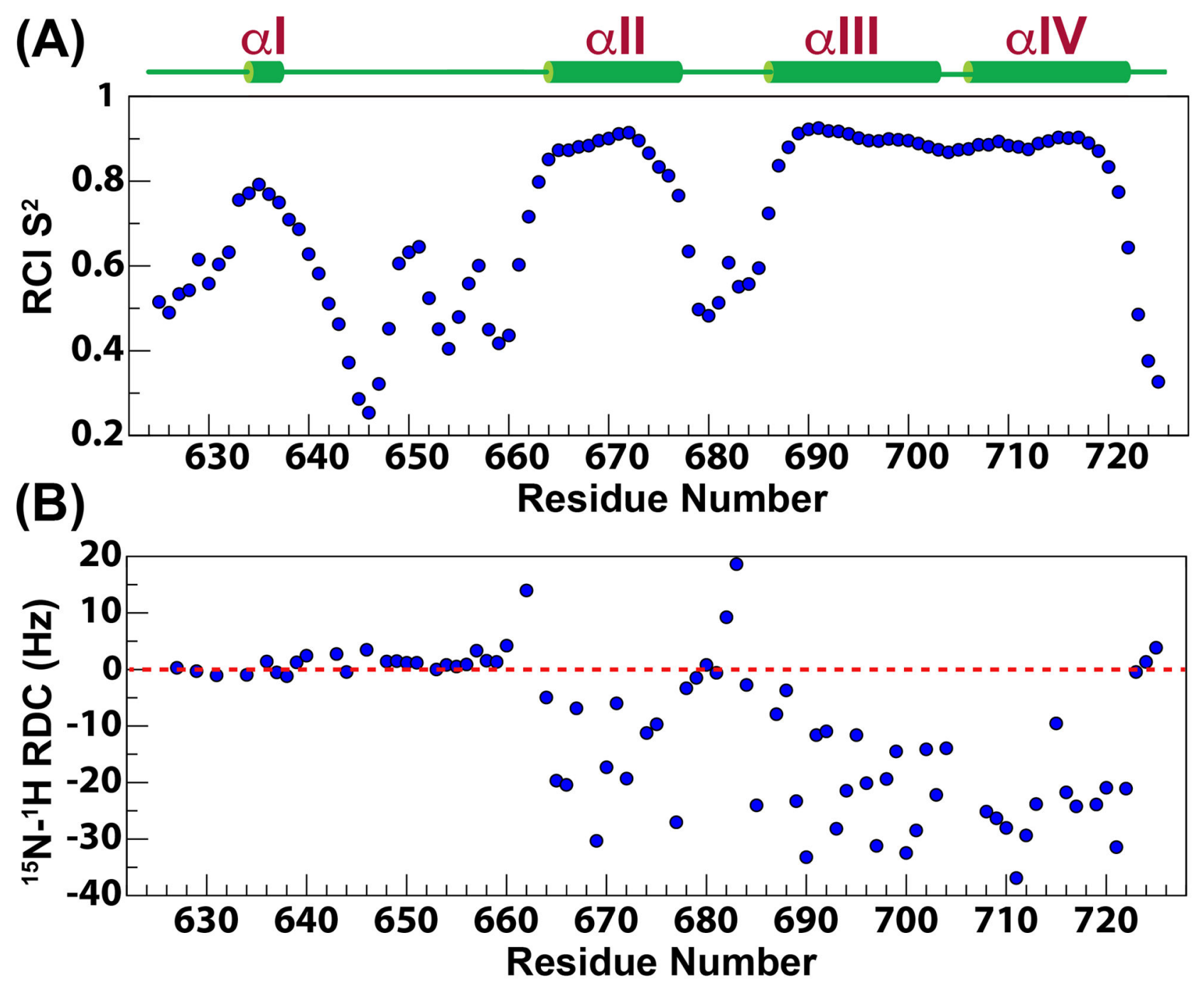

Figure 5.

Random Coil Index (RCI) derived $\mathrm{S}^{2}$ values $(\mathbf{A})$ and ${ }^{15} \mathrm{~N}-{ }^{1} \mathrm{H}$ residual dipolar couplings (RDCs) (B) measured using Pf1 phage for the eEF-2 $\mathrm{K}_{627-725}$ construct are plotted against residue number. 
(A)

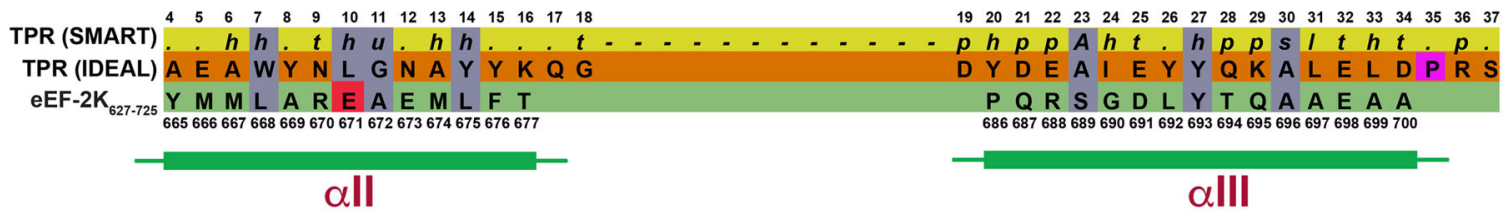

(B)

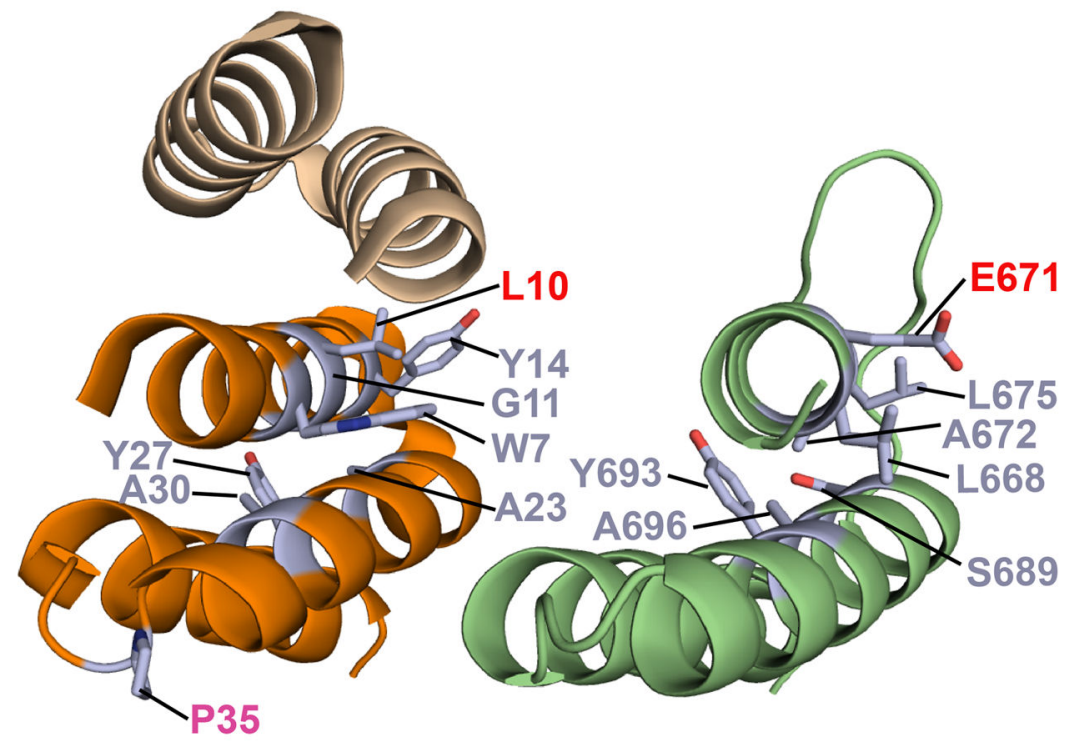

Figure 6.

(A) Comparison of sequence preferences ( $80 \%$ consensus) of the TPR motif predicted by SMART (top), the idealized TPR motif defined by Main et. al $^{62}$ (middle) and the eEF-2 $\mathrm{K}_{627-725}$ sequence (bottom). Conserved residue types are shaded purple; E671 on eEF-2 $\mathrm{K}_{627-725}$ that deviates from the large hydrophobic group expected at this position is shaded red. The proline residue that is preferred at position 35 (shaded magenta) beyond the second helix, is missing in eEF-2 $\mathrm{K}_{627-725}$. For the PFAM preferences, $h, t, u, a, p$ and $s$ denote hydrophobic, turn-like, tiny, aromatic, polar and small, respectively. Also see Figure S3. (B) Comparison between the structures of the idealized TPR (left; the portion that aligns with aII and aIII on eEF-2 $\mathrm{K}_{627-725}$ is shown in orange) and eEF-2 $\mathrm{K}_{627-725}$ (right; only helices II and III are shown). Key residues (colored light purple) from the sequence comparison in (A), are indicated. Similar residues are labeled in light purple; E671 (and the corresponding L10) that deviates from the expected consensus residue type is labeled in red; helix aIII for eEF-2 $\mathrm{K}_{627-725}$ is longer by a turn than the idealized TPR; P35 (labeled in magenta) is missing in eEF-2 $\mathrm{K}_{627-725}$. 


\section{Table 1}

Refinement and structure statistics for eEF-2K $627-725$

\begin{tabular}{|l|c|c|}
\hline \multicolumn{3}{|c|}{ Pairwise Cartesian RMS deviation $(\AA)$} \\
\hline & All & Core \\
\hline Global backbone heavy atoms & $3.92 \pm 2.12$ & $0.93 \pm 0.32$ \\
\hline Global heavy atoms & $4.56 \pm 1.85$ & $1.79 \pm 0.32$ \\
\hline Ordered backbone heavy atoms & $1.18 \pm 0.37$ & $0.42 \pm 0.10$ \\
\hline Ordered heavy atoms & $2.08 \pm 0.41$ & $1.41 \pm 0.16$ \\
\hline
\end{tabular}

\begin{tabular}{|l|c|c|}
\hline \multicolumn{3}{|c|}{ Restraint information } \\
\hline NOEs: Intra-residue & 530 & 365 \\
\hline NOEs: Sequential $(\Delta=|\mathrm{i}-\mathrm{j}|=1)$ & 317 & 205 \\
\hline NOEs: Medium $(5>\Delta=|\mathrm{i}-\mathrm{j}| \geq 2)$ & 221 & 174 \\
\hline NOEs: Long $(\Delta=|\mathrm{i}-\mathrm{j}| \geq 5)$ & 183 & 168 \\
\hline Dihedral angle restraints $(\phi, \psi)$ & 122 & 98 \\
\hline Inter-vector projection angle restraints & 565 & 565 \\
\hline Hydrogen-bond restraints & 70 & 68 \\
\hline
\end{tabular}

\begin{tabular}{|l|c|}
\hline \multicolumn{2}{|c|}{ Energies, NOE Statistics } \\
\hline Total $\left(\mathrm{KCal} \cdot \mathrm{mol}^{-1}\right)$ & $-4314 \pm 69$ \\
\hline Electrostatic $\left(\mathrm{KCal} \cdot \mathrm{mol}^{-1}\right)$ & $-4193 \pm 70$ \\
\hline van Der Waals $\left(\mathrm{KCal} \bullet \mathrm{mol}^{-1}\right)$ & $-895 \pm 10$ \\
\hline Conformers NOEs RMS $(\AA)$ & $0.17 \pm 0.04$ \\
\hline
\end{tabular}

\begin{tabular}{|c|c|}
\hline Conformers NOEs RMS $(\AA)$ & \\
\hline \multicolumn{2}{|c|}{ Ramachandran statistics $(\%)$} \\
\hline
\end{tabular}

\begin{tabular}{|l|c|c|}
\hline Most favored regions & 82.2 & 90.9 \\
\hline Additionally allowed regions & 15.6 & 7.3 \\
\hline Generously allowed regions & 1.1 & 1.8 \\
\hline Disallowed regions & 1.1 & 0 \\
\hline Average RMS Z-scores for deviation from current reliable structures \\
\hline Bond lengths & $0.22 \pm 0.01$ & $0.20 \pm 0.01$ \\
\hline Bond angles & $0.38 \pm 0.01$ & $0.33 \pm 0.02$ \\
\hline Omega angle restraints $\left(^{\circ}\right)$ & $0.59 \pm 0.04$ & $0.56 \pm 0.06$ \\
\hline Side-chain planarity & $0.43 \pm 0.12$ & $0.46 \pm 0.17$ \\
\hline Improper dihedral distribution & $0.45 \pm 0.09$ & $0.47 \pm 0.13$ \\
\hline Inside/Outside distribution & $1.16 \pm 0.03$ & $1.06 \pm 0.02$ \\
\hline
\end{tabular}

Average RMS Z-scores for deviation from current reliable structures

\begin{tabular}{|l|c|c|}
\hline 1st generation packing quality & $-2.48 \pm 0.15$ & $-0.56 \pm 0.18$ \\
\hline 2nd generation packing quality & $-2.84 \pm 0.38$ & $-0.87 \pm 0.39$ \\
\hline$\chi 1 / \chi 2$ rotamer normality & $-1.75 \pm 0.73$ & $-1.19 \pm 0.69$ \\
\hline Backbone conformation & $-0.86 \pm 0.35$ & $1.61 \pm 0.25$ \\
\hline
\end{tabular}

